\title{
SEROPREVALENCE AND RISK FACTORS OF SYPHILIS AMONG HIV/AIDS PATIENTS IN ISTANBUL, TURKEY
}

\author{
Özlem Altuntaş Aydın ${ }^{1}$, Hayat Kumbasar Karaosmanoğlu' ${ }^{1}$, Murat Sayan², Emine Rahşan İnce ${ }^{1}$, Özcan Nazlıcan ${ }^{1}$ \\ 'Department of Infectious Diseases and Clinical Microbiology, Haseki Training and Research Hospital, Istanbul, Turkey \\ ¿University of Kocaeli, Kocaeli, Turkey
}

\section{SUMMARY}

Objective: Data on syphilis seroprevalence among human immunodeficiency virus (HIV)/Acquired immunodeficiency syndrome (AIDS) patients are unavailable in Turkey although they have common transmission routes. Our study is oriented towards the assessment of the seroprevalence of syphilis and the related risk factors in the HIVIAIDS patients followed in our outpatient clinic.

Materials: Newly diagnosed HIVIAIDS cases $(n=308)$ who attended our outpatient clinic between January 2006 and April 2013 were included in the study. Patient characteristics, medical history, physical examination findings, CD4 ${ }^{+}$T lymphocyte count, HIV RNA level, rapid plasma reagent (RPR) and Treponema pallidum hemagglutination (TPHA) test results were analyzed retrospectively. TPHA positivity was considered indicative of syphilis-causing T. pallidum exposure.

Results: HIV infection was transmitted through heterosexual $(n=176)$ or homosexual $(n=131)$ contact (266 male, 86.3\%; age $38.3 \pm 11.7$ years; CD4+ T lymphocyte count, $\left.330.6 \pm 15.17 / \mathrm{mm}^{3}\right) .50 .7 \%$ of the patients attained only primary education. Out of the 245 cases, who were asked about the number of their sexual partners, 40 patients ( 26 women) lived in a monogamous relationship. Condom usage was not practiced (57.2\%) or was only occasional (34.4\% - particularly with their legal spouses and for contraception). Physical exam revealed no signs of syphilis or other STIs. TPHA (+/- RPR) positivity was determined in 40 patients (12.9\%), indicating T. pallidum exposure. All patients with positive syphilis serology were male $(p=0.0026)$. T. pallidum exposure was determined in $21.3 \%$ of homosexual and $6.8 \%$ of heterosexual cases $(p=0.0003)$.

Conclusion: Since sexual contact is the most common route of transmission for both infections, syphilis seroprevalence was relatively high in our HIVIAIDS patients. Male and homosexual HIVIAIDS patients constituted a group at the highest risk for syphilis.

Key words: syphilis, HIV, epidemiology, Turkey, seroprevalence

Address for correspondence: Ö. A. Aydın, Haseki Training and Research Hospital, Department of Infectious Diseases and Clinical Microbiology, Aksaray-Fatih, Istanbul, Turkey. E-mail: ozlemaa@gmail.com

\section{INTRODUCTION}

Sexually transmitted infections (STI) cause serious public health problems in many parts of the world. Syphilis is an STI caused by Treponema pallidum. Unprotected sexual contact, blood transfusion, vertical transmission from mother to baby are the main transmission routes for syphilis and human immunodeficiency virus (HIV) infections (1). The relationship between HIV and syphilis has not been clearly identified despite 30 years of clinical experience (2). HIV/AIDS patients with early-stage syphilis have greater HIV transmission risk due to the presence of genital/oral ulcers, decreased $\mathrm{CD} 4^{+} \mathrm{T}$ lymphocyte count and increased viral load. On the other hand, impaired cellular and humoral immunity in HIV infection lowers host defense against T. pallidum, leading to changes in the natural course and clinic progression of syphilis, shortened incubation time, and increased number and infectiousness of syphilis lesions $(3,4)$. Therefore, international guidelines recommend periodic serological testing of syphilis in all HIV-infected patients $(5,6)$. The first case of HIV/AIDS in Turkey was reported in 1985 . The current number of HIV-infected cases in Turkey is 6,188 according to the surveillance conducted by the Turkish Ministry of Health from October 1985 to December 2012 (7). In a recent study of antiretroviral naive HIV-1 infected patients, sexual contact was predominantly reported as an infection transmission route - heterosexual contact in $64 \%$ and homosexual contact in $32 \%$ of cases (8). An increase in the number of HIV/AIDS patients as a sexually active group has been observed in Turkey, which might have led to an increase in the number of syphilis cases. In Turkey, various investigations on potential risk groups revealed syphilis seroprevalence as $0.11 \%$ among blood donors, $4.4-9.1 \%$ among sex workers, and $14 \%$ among homosexual men (9-12). Even though they share transmission routes, there are no data on syphilis seroprevalence of HIV/AIDS cases in Turkey. This study intends to determine the seroprevalence of syphilis and investigate the related risk factors among HIV/AIDS patients followed in our outpatient clinic.

\section{MATERIALS AND METHODS}

All HIV/AIDS patients newly-diagnosed by Western Blot verification test (HIV BLOT 2.2, MP Biomedicals Asia Pacific, Singapore) who visited our clinic $(n=308)$ during the period from January 2006 to April 2013 were included in the study. Patients' files containing records on age, gender, education level, marital status, probable transmission route of HIV infection, number of 
sexual partners, condom usage, history of STIs and STI treatments, physical exam, CD4 ${ }^{+} \mathrm{T}$ lymphocyte count, HIV RNA levels, rapid plasma reagent (RPR), and Treponema pallidum hemagglutination test (TPHA) results were analyzed.

As a part of the physical examination, routine evaluation for STIs was performed by infectious disease and clinical microbiology specialists and consultation with dermatology, gynecology, and urology specialists, when necessary. $\mathrm{CD}^{+} \mathrm{T}$ lymphocyte count was determined using standard flow cytometry (FACScalibur, Becton Dickinson, New Jersey, USA). HIV RNA level was measured by PCR (COBAS Ampliprep/COBAS TaqMan HIV-1 Test, Roche Molecular Systems, USA). Serum RPR (Spinreact, Spain) and TPHA (Spinreact, Spain) tests were used together for the syphilis screening. TPHA positivity (with positive or negative RPR) was considered indicative of exposure to the syphiliscausing agent $T$. pallidum.

Graphpad Prism 5.01 (GraphPad Software, Inc, CA, USA) was used for the statistical analysis and graphical drawings of the study. Plasma CD4 and HIV RNA levels were shown as mean \pm SEM. Plasma CD4 and HIV RNA levels were compared between groups using unpaired t test. Fisher's exact Chi-square test was used for the comparison of the groups by gender, Yates-corrected Chi-square for the comparison of the transmission route of HIV infection, and Chi-square for the comparison of all other nonparametric variables (condom usage, number of partners, marital status, education level and age). The level of significance was set at $\mathrm{p}<0.01$ for Fisher's exact Chi-square test and $\mathrm{p}<0.001$ for Yates-corrected Chi-square test.

\section{RESULTS}

All cases $(n=308)$ included in the analysis were infected with HIV-1. Mean age was $38.3 \pm 11.7$ and $266(86.3 \%)$ were male. Mean $\mathrm{CD}^{+} \mathrm{T}$ lymphocyte count was $330.6 \pm 15.1 / \mathrm{mm}^{3}$ during the first visit. Probable transmission route of HIV infection was heterosexual contact in 176 patients $(57.1 \%)$ and homosexual contact in 131 patients $(42.5 \%)$. Only one female patient was thought to have contracted HIV infection through intravenous substance use. None of the cases showed any signs of syphilis or other STIs during the physical examination. Six patients had a history of syphilis infection, while 4 patients had a history of gonorrhea, and all 10 patients were treated for their infections. Five of the patients with a history of syphilis were treated with benzathine penicillin $\mathrm{G}$, and the other patient was administered doxycycline due to known allergy to penicillin. The statistical relationship between syphilis seropositivity and age, gender, education level, marital status, transmission of HIV infection, number of sexual partners, condom usage, $\mathrm{CD}^{+} \mathrm{T}$ lymphocyte count, and HIV RNA levels was investigated and presented in Table 1.

Forty patients $(12.9 \%)$ in total were considered to have been exposed to T. pallidum, 26 of whom were RPR and TPHA positive, and 14 were RPR negative but TPHA positive. RPR positivity was found in 1:2 titer in seven patients, 1:4 titer in 16 patients, and 1:8 titer in three patients. Of 14 patients with negative RPR and positive TPHA, 6 were previously treated for syphilis.

All patients with positive syphilis serology were male $(\mathrm{p}=0.0026)$. Just $21(8.4 \%)$ out of 250 patients were using condom routinely. Twenty eight of 131 homosexual patients (21.4\%) and 12 of 176 heterosexual patients $(6.8 \%)$ were exposed to $T$. pallidum $(\mathrm{p}=0.0003)$.

\section{DISCUSSION}

RPR and TPHA are complementary tests used together to screen such risk groups as sex workers, and yield the most accurate result in defining all the stages of syphilis (13-15). Results from our study indicate that $12.9 \%$ of HIV/AIDS patients have been exposed to T. pallidum. Syphilis seroprevalence in newly diagnosed HIV infected individuals was reported as $19.6 \%$ in China, $5.3 \%$ in Iran, $4.6-6.2 \%$ in Holland, $7 \%$ in men and $13 \%$ in women in USA (16-19). Although our results are in accordance with the foregoing studies, social, cultural and economic differences between countries may affect the frequency of STIs. In terms of education, half of our HIV infected patients $(50.7 \%)$ were primary school graduates, although no significant relationship was found between education and syphilis seroprevalence. In terms of marital status, more than half of our patients were married. Eleven of the widowed patients had lost their spouse because of HIV infection. Ten of these patients were monogamous women infected by their spouses. This is the result of multiple partnerships of husbands of monogamous Turkish women. Eighty seven percent of our cases had multiple sexual partners. Although syphilis seroprevalence was increasing with increasing number of sexual partners, the relationship was not statistically significant.

Sexually transmitted disease report from the Centers for Disease Control and Prevention (USA) for the year 2011 indicates that syphilis prevalence is increasing among homosexual and bisexual men (20). The reasons for increase in syphilis prevalence among HIV infected homosexual men are stated as multiple sexual partners, poor condom usage, finding HIV infected sexual partners on the Internet and common use of psychostimulants and drugs that improve sexual performance $(21,22)$. In addition, prevalence of syphilis is increased among homosexual men due to a common belief that oral sex is "safer" regarding transmission of HIV infection, while syphilis may be transmitted through oral ulcer lesions $(23,24)$. Similar arguments are valid for statistically significantly higher syphilis seroprevalence among homosexual men compared to heterosexual men in our study. It is also noteworthy that in this study all syphilis seropositive patients were male. This male dominance is thought to be related to the high percentage of homosexual men $(n=28,70 \%)$ among the 40 men detected as syphilis seropositive. Male patients having multiple partners (unregistered sex workers and foreign partners) further contributed to this gender bias.

Routine and correct use of latex condom is fairly effective for protection against HIV, syphilis and other STIs (25). However, the frequency of patients indicating routine condom use was low $(8.4 \%)$ and routine condom use was adopted mostly after being infected with HIV. In fact, almost none of our patients practice routine condom use, and prefer condom use only with their legal spouse and for the purpose of contraception, which may account for not detecting a significant association between syphilis seroprevalence and condom usage. In studies of the syphilis effect on $\mathrm{CD}^{+} \mathrm{T}$ lymphocyte count and HIV RNA levels, syphilis was determined to cause a transient increase in viral load and decrease in $\mathrm{CD}^{+} \mathrm{T}$ lymphocyte count, which improved after treatment, 
Table 1. Demographic characteristics and laboratory findings of the patients $(n=308)$ according to syphilis seropositivity

\begin{tabular}{|c|c|c|c|}
\hline & $\begin{array}{c}\text { TPHA (+) } \\
\mathrm{n}(\%)\end{array}$ & $\begin{array}{c}\text { TPHA (-) } \\
n(\%)\end{array}$ & $\mathrm{p}$ \\
\hline \multicolumn{4}{|l|}{ Gender } \\
\hline Female & 0 & 42 & \multirow{2}{*}{$0.0026^{*}$} \\
\hline Male & 40 & 226 & \\
\hline \multicolumn{4}{|l|}{ Age } \\
\hline $20-40$ & 23 & 168 & \multirow{3}{*}{0.74} \\
\hline $41-60$ & 16 & 91 & \\
\hline$\geq 61$ & 1 & 9 & \\
\hline \multicolumn{4}{|l|}{ Education } \\
\hline Illiterate & 2 & 4 & \multirow{4}{*}{0.37} \\
\hline Primary school & 15 & 120 & \\
\hline Secondary or high school & 9 & 78 & \\
\hline College & 7 & 43 & \\
\hline \multicolumn{4}{|l|}{ Marital status } \\
\hline Married & 19 & 145 & \multirow{3}{*}{0.73} \\
\hline Single & 16 & 94 & \\
\hline Widowed & 5 & 29 & \\
\hline \multicolumn{4}{|l|}{ Transmission of HIV infection } \\
\hline Heterosexual intercourse & $12(6.8 \%)$ & $164(93.2 \%)$ & \multirow{2}{*}{$0.0003^{* *}$} \\
\hline Homosexual intercourse & $28(21.4 \%)$ & $103(78.6 \%)$ & \\
\hline \multicolumn{4}{|l|}{ Number of sexual partners } \\
\hline 1 & 1 & 39 & \multirow{4}{*}{0.09} \\
\hline $2-10$ & 30 & 146 & \\
\hline $11-20$ & 2 & 18 & \\
\hline$\geq 20$ & 2 & 7 & \\
\hline \multicolumn{4}{|l|}{ Condom usage } \\
\hline No & 17 & 126 & \multirow{3}{*}{0.94} \\
\hline Yes & 3 & 18 & \\
\hline Occasional & 11 & 75 & \\
\hline CD4+ T lymphocyte count $\left(/ \mathrm{mm}^{3}\right)$ & $323.9 \pm 31.7$ & $335.5 \pm 16.2$ & 0.79 \\
\hline HIV RNA level (copy/ml) & $909100 \pm 378100$ & $905700 \pm 253200$ & 0.99 \\
\hline
\end{tabular}

${ }^{*}$ Fisher's exact test, $p<0.01 ;{ }^{* *}$ Yates-corrected Chi-square test, $p<0.001$.

Data are given as number of patients (n).

similar to the effects observed in other acute infections $(26,27)$. In our study, no difference was detected in terms of $\mathrm{CD}^{+} \mathrm{T}$ lymphocyte count and HIV RNA levels in syphilis seropositive and seronegative patients, which could be explained by the absence of early stage syphilis in our patient population.

In conclusion, transmission route of HIV infection was either heterosexual or homosexual contact, in accordance with the HIV/ AIDS patient's profile in Turkey. Since the main mode of transmission was sexual, syphilis seroprevalence was high in our patient group. Male and homosexual HIV/AIDS patients were determined as a group at highest risk of syphilis. Following syphilis serology in all HIV infected cases is critically important for early stage recognition and treatment, and hence to lessen the likelihood of further transmission of either infection.

\section{Conflict of Interests}

None declared

\section{REFERENCES}

1. Lynn WA, Lightman S. Syphilis and HIV: a dangerous combination. Lancet Infect Dis. 2004 Jul;4(7):456-66.

2. Zetola NM, Klausner JD. Syphilis and HIV infection: an update. Clin Infect Dis. 2007 May 1;44(9):1222-8.

3. Buchacz K, Patel P, Taylor M, Kerndt PR, Byers RH, Holmberg SD, et al. Syphilis increases HIV viral load and decreases CD4 cell counts in HIV-infected patients with new syphilis infections. AIDS. 2004 Oct 21;18(15):2075-9.

4. Schöfer H, Imhof M, Thoma-Greber E, Brockmeyer NH, Hartmann M, Gerken G, et al.; The German AIDS Study Group (GASG). Active syphilis in HIV infection: a multicentre retrospective survey. Genitourin Med. 1996 Jun;72(3):176-81.

5. EACS Guidelines. Version 6.1 - November 2012. Paris: EACS; 2012.

6. Centers for Disease Control and Prevention. HIV infection: detection, counseling, and referral. Sexually transmitted diseases treatment guidelines [Internet]. CDC; 2010 [cited 2013 Aug 29]. Available from: http:/ www.cdc.gov/std/treatment $/ 2010 /$ hiv.htm.

7. Turkish Ministery of Health. Distrubution of HIV/AIDS patients by years in Turkey [Internet]. [cited 2013 Aug 29]. Available from: http://www. hatam.hacettepe.edu.tr/verilerAralik2012.pdf. (In Turkish.) 
8. Sayan M, Kumbasar Karaosmanoğlu H, Mete B, Gündüz A, Aydın O, Yemișen M, et al. Molecular epidemiological analysis of HIV-1 pol gene sequences isolated in Istanbul, Turkey. Mikrobiyol Bul. 2013 Jan;47(1):87-97. (In Turkish.)

9. Oncul O, Emekdas G, Cavuslu S, Artuk C, Aksoy A. The sixteen-year trend of syphilis in Turkey: data from blood donors. Trop Doct. 2008 Jul;38(3):181-2.

10. Akın L. Epidemiology of sexually transmitted infection: review. Turkiye Klinikleri J Med Sci. 2006;26(6):655-65. (In Turkish.)

11. Orak S, Dalkiliç AE, Ozbal Y. Serological investigation of HIV infections, HBsAg and syphilis in prostitutes in Elaziğ. Mikrobiyol Bul. 1991 Jan;25(1):51-6. (In Turkish.)

12. İnci R, Özbakkaloğlu B, Bilgiç A, Tümbay E, Akı A, Taşdelen N. Syphilis antibodies in homosexual men. Ege T1p Dergisi. 1990;29:958-60. (In Turkish.)

13. Aktaş G. Serological diagnosis of syphilis. Türk Mikrobiyol Cemiy Derg. 2005;35(1):73-9. (In Turkish.)

14. Karaca Y, Cöplü N, Gözalan A, Oncül O, Akin L, Esen B. Establishment of an algorithm for serological testing of syphilis identification. Mikrobiyol Bul. 2010 Jan;44(1):35-45. (In Turkish.)

15. Workowski KA, Berman S; Centers for Disease Control and Prevention (CDC). Sexually transmitted diseases treatment guidelines, 2010. MMWR Recomm Rep. 2010 Dec 17;59(RR-12):1-110.

16. Zhao YS, Su SI, Lv CX, Zhang XF, Lin L, Sun XG, et al. Seroprevalence of hepatitis C, hepatitis B virus and syphilis in HIV-1 infected patients in Shandong, China. Int J STD AIDS. 2012 Sep;23(9):639-43.

17. Badie BM, Yavari Z, Esmaeeli S, Paydary K, Emamzadeh-Fard S, Seyed Alinaghi SA, et al. Prevalence survey of infection with Treponema pallidum among HIV-positive patients in Tehran. Asian Pac J Trop Biomed. 2013 Apr;3(4):334-6.

18. Klausner JD. Frequency of syphilis testing in HIV-infected patients: more and more often. Sex Transm Dis. 2009 Feb;36(2):86-7.

19. Seña AC, Torrone EA, Leone PA, Foust E, Hightow-Weidman L. Endemic early syphilis among young newly diagnosed HIV-positive men in a southeastern U.S. state. AIDS Patient Care STDS. 2008 Dec;22(12):95563.
20. US Department of Health and Human Services, Centers for Disease Control and Prevention, Division of STD Prevention. Sexually transmitted disease surveillance 2011 [Internet]. Atlanta: US Department of Health and Human Services; 2012 [cited 2013 Aug 29]. Available from: http:// cdc.gov/std/stats11/Surv2011.pdf.

21. Kim AA, Kent CK, Klausner JD. Increased risk of HIV and sexually transmitted disease transmission among gay or bisexual men who use Viagra, San Francisco 2000-2001. AIDS. 2002 Jul 5;16(10):1425-8

22. Wong W, Chaw JK, Kent CK, Klausner JD. Risk factors for early syphilis among gay and bisexual men seen in an STD clinic: San Francisco, 20022003. Sex Transm Dis. 2005 Jul;32(7):458-63.

23. Page-Shafer K, Shiboski CH, Osmond DH, Dilley J, McFarland W, Shiboski SC, et al. Risk of HIV infection attributable to oral sex among men who have sex with men and in the population of men who have sex with men. AIDS. 2002 Nov 22;16(17):2350-2.

24. Marcus U, Bremer V, Hamouda O, Kramer MH, Freiwald M, Jessen H, et al; MSM-STD-Sentinel Network. Understanding recent increases in the incidence of sexually transmitted infections in men having sex with men: changes in risk behavior from risk avoidance to risk reduction. Sex Transm Dis. 2006 Jan;33(1):11-7.

25. Adler MW. Sexually transmitted diseases control in developing countries. Genitourin Med. 1996 Apr;72(2):83-8.

26. Sadiq ST, McSorley J, Copas AJ, Bennett J, Edwards SJ, Kaye S, et al. The effects of early syphilis on CD4 counts and HIV-1 RNA viral loads in blood and semen. Sex Transm Infect. 2005 Oct;81(5):380-5.

27. Kofoed K, Gerstoft J, Mathiesen LR, Benfield T. Syphilis and human immunodeficiency virus (HIV)-1 coinfection: influence on CD4 T-cell count, HIV-1 viral load, and treatment response. Sex Transm Dis. 2006 Mar;33(3):143-8.

Received December 25, 2013 Accepted in revised form Jannuary 5, 2015 